\title{
Late Holocene Pollen Sequence of the Ilan Plain, Northeastern Taiwan, and its Environmental and Climatic Implications
}

\author{
Shu-Fen Lin ${ }^{1,2, *}$, Ping-Mei Liew ${ }^{1}$, and Tzu-Hua Lai ${ }^{3}$ \\ (Manuscript received 29 December 2003, in final form 27 April 2004)
}

\begin{abstract}
Pollen analysis of a $15.0 \mathrm{~m}$ core covering the past 3500 years from the Ilan Plain, northeastern Taiwan, displays a record of environmental changes and climate trends for the late Holocene. At about 3500 yr B.P., brackish water-tolerant elements, such as Bruguiera and Acrostichum, dominated the vegetation, reflecting that the environment was influenced by marine excursions. Following this period, wetland elements Poaceae and Cyperaceae were abundant between ca. 3350 and ca. 3100 yr B.P. Then pioneer taxon Alnus increased at the expense of those herbs in the later part of the interval ca. 3100 and ca. 2000 yr B.P. This suggests a shift from a primarily coastal (ca. $3500 \mathrm{yr}$ B.P.) to wetland (ca. $3350 \mathrm{yr}$ B.P.) and then finally terrestrial (ca. 2000 yr B.P.) environment at the coring site. Since then, the present fluvial plain has existed. Humidity conditions which were interpreted from the amount and variations of fern spore probably indicate a strengthening of the monsoon at ca. 3200, ca. 2000, and ca. $900 \mathrm{yr}$ B.P., respectively. The Medieval Warm Period is also apparent indicated by the amount of arboreal elements based on pollen concentrations ca. 1300 to ca. $900 \mathrm{yr}$ B.P. Significant human-induced vegetation changes occurred between ca. 1300 and ca. 900 yr B.P. and over the last 400 years.
\end{abstract}

(Key words: Pollen record, Late Holocene, Monsoon, Environmental changes, Human impact, Ilan Plain)

\footnotetext{
${ }^{1}$ Institute of Geosciences, National Taiwan University, Taipei, Taiwan, ROC

${ }^{2}$ Institute of History and Philology, Academia Sinica, Taipei, Taiwan, ROC

${ }^{3}$ Central Geological Survey, MOEA, Taipei, Taiwan, ROC

* Corresponding author address.Dr. Shu-Fen Lin, Institute of Geosciences, National Taiwan University, Taipei, Taiwan, ROC, E-mail: afen@mail.ihp.sinica.edu.tw
} 


\section{INTRODUCTION}

To detail fluctuations in climatic conditions during the late Holocene is one of the more challenging aspects of palynological study compared with conspicuous Pleistocene glacial interglacial changes. Here, pollen studies in a site of rapid sedimentation ought to be useful in interpreting the climatic history of the last several millennia. The Ilan Plain, facing the Pacific in northeastern Taiwan with an area of ca. $330 \mathrm{~km}$ square is geologically situated near the west end of the offshore Okinawa Trough (Fig. 1). This Plain is presently undergoing a serious subsidence and has an extremely high sedimentation rate due to the southwestward extension of the Okinawa Trough (Suppe 1984; Letouzey and Kimura 1986; Yeh et al. 1989; Liu 1995; Lai and Hsieh 2003). Twenty-meter thick sediments are found within the last 3000 years and the Holocene sediments reach 120 meters-thick based on drilling cores (Chen W. S. 2000; Central Geological Survey 2001). The existence of scattered wetlands and swamps in this deltaic plain provide good sites for studying climatic and environmental changes owing to the abundance of organic matter. In this paper, we present radiocarbon-dated pollen stratigraphy from a drilling core collected from Wuyuan, a former wetland marsh and mutually an archaeological site in Ilan Plain. The data has been interpreted in the context of climatic and environmental changes, and furthermore, we also discuss human impact, when it occurred, over the past 3500 years.

\section{STUDY REGION}

With an almost equilateral triangular shape, the Ilan Plain, an alluvial fan, tilts moderately to the east (Fig. 1). Facing the Pacific eastward and surrounded by steep mountains in the northwest and southwest, the plain is geographically isolated. Forceful monsoons have deposited scattered sand dunes in the coastal region, impeding the rivers, and forming a series of wetlands behind the dunes from north to south. Due to being only 1 2 $\mathrm{m}$ above sea level, these wetlands are frequently subject to seawater floods during flood tides and form a sensitive ecosystem.

The climate of the region is subtropical, humid, and is strongly influenced by the East Asian monsoon. Although derived from the cooler and drier area of the Asian mainland, the winter monsoon becomes vapor-saturated as it passes over the ocean before arriving Taiwan. The funnel-shaped topography of the plain also enhances its rainfall. Thus Ilan area is famous for its high precipitation levels, especially in fall and winter when the winter monsoon prevails (Chiang 1995). According to the records from 1936 to 2003 AD at Ilan Weather Station, the mean annual temperature is $22.1^{\circ} \mathrm{C}$ with an average low of $15.9^{\circ} \mathrm{C}$ for the coldest month (January) and $28.2^{\circ} \mathrm{C}$ for the warmest month (July). Annual precipitation is very high (ca. $2760 \mathrm{~mm}$ ), with the greatest amount in September, October, and November (Chiang 1995; Central Weather Bureau 2002). Thus it is almost never subject to drought and can experience flooding in fall.

The natural vegetation of lowlands and hills in Ilan is a subtropical evergreen rain forest although the biome is highly dependent on topography and altitude ( $\mathrm{Su} \mathrm{1984).} \mathrm{The} \mathrm{vegetation}$ 


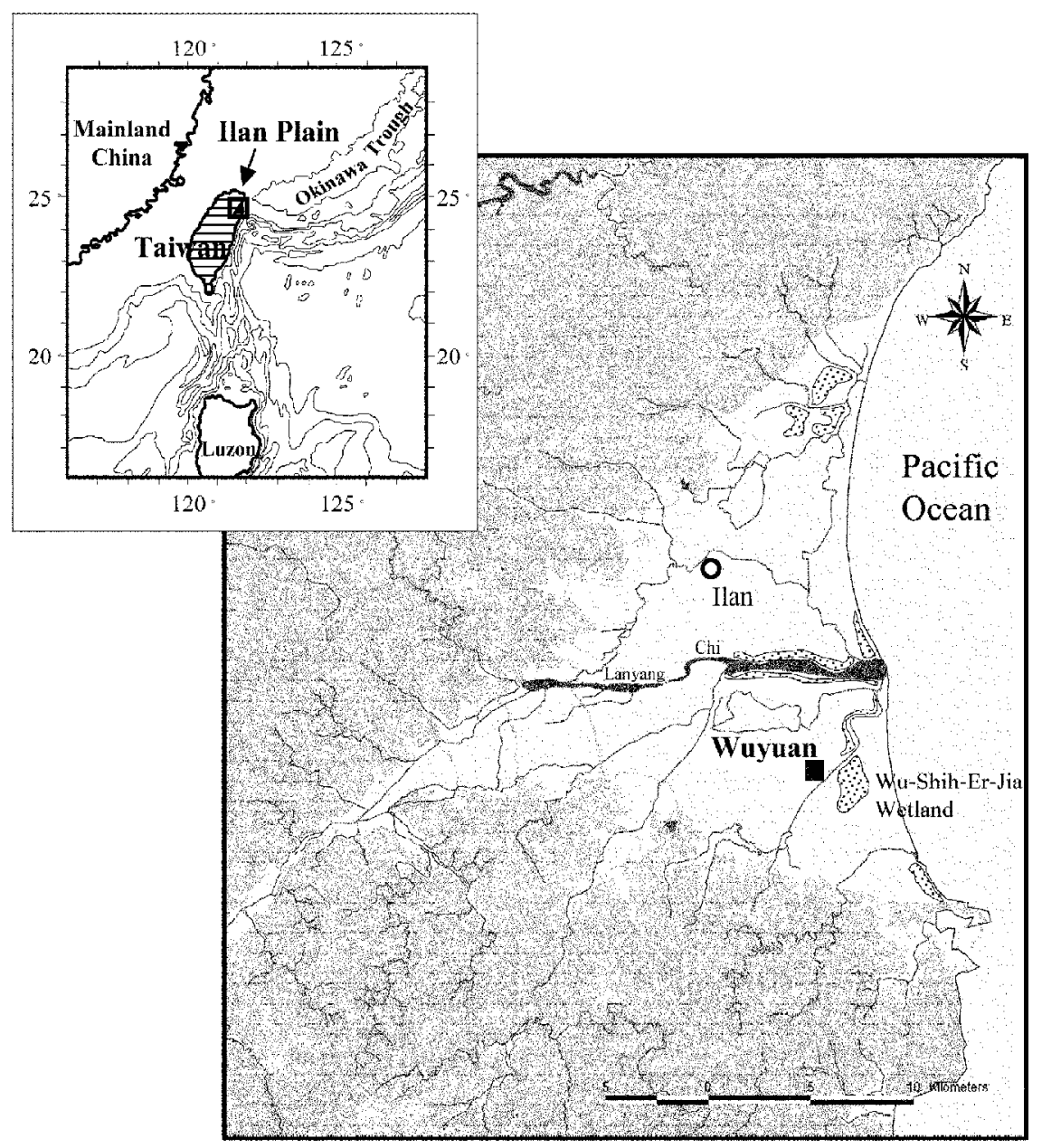

Fig. 1. Locations of the Ilan Plain (upper map) and the Wuyuan site (right map). Dotted pattern areas in the right map indicate wetlands which scattered throughouting in the coastal region.

of the surrounding mountains consists of subtropical to warm temperate forests dominated by elements common to the Castanopsis-Machilus forest zone (Chen T. Y. 2000). Among the characteristic tree taxa are various kinds of hard wood species like Castanopsis cuspidate var. carlesii form. sessilis, Castanopsis uraiana, Machilus japonica var. kusanoi, Ardisia seiboldii, Ficus fistulosa var. fistulosa, Engelhardia roxburghiana, Cyclobanopsis pachyloma, Elaeocarpus japonicus, Bischoffia javanica, and Lagerstroemia subcostata. In the very recent past, the vegetation was dominated by Alnus formosana in the riverine area and alluvial fan of the plain (Chen T. Y. 2000). However, the lowlands are now subject to cultivation and land clearing due to rapid urban development. Shrubbery, such as Barringtonia racemosa and 
Cephalanthus naucleoide, is presently scattered along the riverbanks. The main components of coastal wetland marsh are Poaceae, Cyperaceae, and aquatic flora like Typha orientalis (Kuo 1993).

\section{MATERIALS AND METHODS}

Wuyuan is situated in the southern part of the Ilan Plain near Wu-Shih-Er-Jia Wetland (Fig. 1). Currently, Phragmites communis and Cyperus malaccensis are the dominant taxa in this slightly brackish swamp(Kuo 1993). Based on archaeological studies, the Wuyuan site, which belongs to the Kavanan Cultivation, appears to have been settled about 400 years ago (Huang 1998).

The Wuyuan Core was undertaken by the Central Geological Survey for the "Groundwater Monitoring Network in Taiwan" project. The core goes down $190 \mathrm{~m}$ in depth. Based on stratigraphy and radiocarbon dates, the lowermost $150 \mathrm{~m}$ of this core is primarily transgressive deposit post the Last Glacial Maximum and the upper $40 \mathrm{~m}$ is terrestrial sediments thereafter (Central Geological Survey 2001). The samples in this study cover the uppermost $15.0 \mathrm{~m}$, of which are muddy to fine sand sediments probably deposited in the last 3500 years.

Lithological units recognized in the upper $15.0 \mathrm{~m}$ are as follows (Fig. 2): Between depths 15.0 and $9.3 \mathrm{~m}$ is an interval of dark gray mud consisting of large amounts of plant materials in the lower section, this organic content decreases gradually the further up the core one observes to $9.3 \mathrm{~m}$. From depths 9.3 to $8.2 \mathrm{~m}$ is a mass of grayish brown fine sand in which organic matter is low. Above $8.2 \mathrm{~m}$ in depth, the sediment is gray mud with some tiny roots between depths 7.7 and $7.5 \mathrm{~m}$. Massive grayish brown mud can be observed at a depth between 7.5 and $6.4 \mathrm{~m}$ and then the organic matter content decreases again. Sediment between depths 6.4 and $5.4 \mathrm{~m}$ is dark gray muddy fine sand, which contains organic matter and charcoals. Above $5.4 \mathrm{~m}$ in depth, the sediment returns to grayish brown mud with low organic matter content. Lithology changes abruptly at $4.0 \mathrm{~m}$ in depth, grayish brown fine sand replaces the massive mud. Above a depth of $2.0 \mathrm{~m}$, the sediments change again into pale yellow mud that contains a good deal of plant material and charcoals.

The available AMS dates, shown in Table 1, are graphically fitted to a depth-age curve (Fig. 2). Dates in the text are reported in calibrated ages. The dates suggest a very rapid sedimentation at the interval between 3400 and $3100 \mathrm{yr}$ B.P. $\left(21.7 \mathrm{~mm} \mathrm{yr}^{-1}\right)$, followed by less rapid sedimentation for the next 2000 years $\left(1.7 \mathrm{~mm} \mathrm{yr}^{-1}\right)$ and an intermediate rate (6.9 $\mathrm{mm} \mathrm{yr}^{-1}$ ) over the last 1000 years. The reason for the dramatic changes in sedimentation rate is not clear. Tectonic movement is one possibility for the abrupt changes due to the frequent earthquakes and the tectonic framework of Ilan Plain.

A total of 110 samples were extracted at $25 \mathrm{~cm}$ intervals from the top $4.0 \mathrm{~m}$ and $10 \mathrm{~cm}$ intervals from depths 4.0 to $15.0 \mathrm{~m}$. Small subsamples $(6 \sim 8 \mathrm{~g})$ of all samples were measured using a Bartington MS2 susceptibility meter to determine magnetic susceptibility in the sediments. Eighty-three samples of $2 \mathrm{ml}$ each were selected for pollen analysis. They were processed according to a procedure slightly modified from Moore et al. 1991, involving treatments with hydrochloric acid, potassium hydroxide, sodium pyrophosphate, and hydrofluoric 
acid. Four tablets containing a known quantity of Lycopodium spores were added to each sample at the beginning of processing to permit calculation of pollen concentration values. The residue was suspended in silicone oil and mounted on slides for microscopic examination at 400x and 1000x magnifications. The fine sand layer between 2.0 and $4.0 \mathrm{~m}$ in depth was pollen scant, though tracer spores were abundant in all samples, thereby assuring that the pollen extraction procedures did not result in pollen loss. The pollen sum consists of at least 200 grains of all pollen taxa except for samples with low pollen counts. Where samples contained large amounts of fern spores, more than 500 grains of pollen and spore were counted.

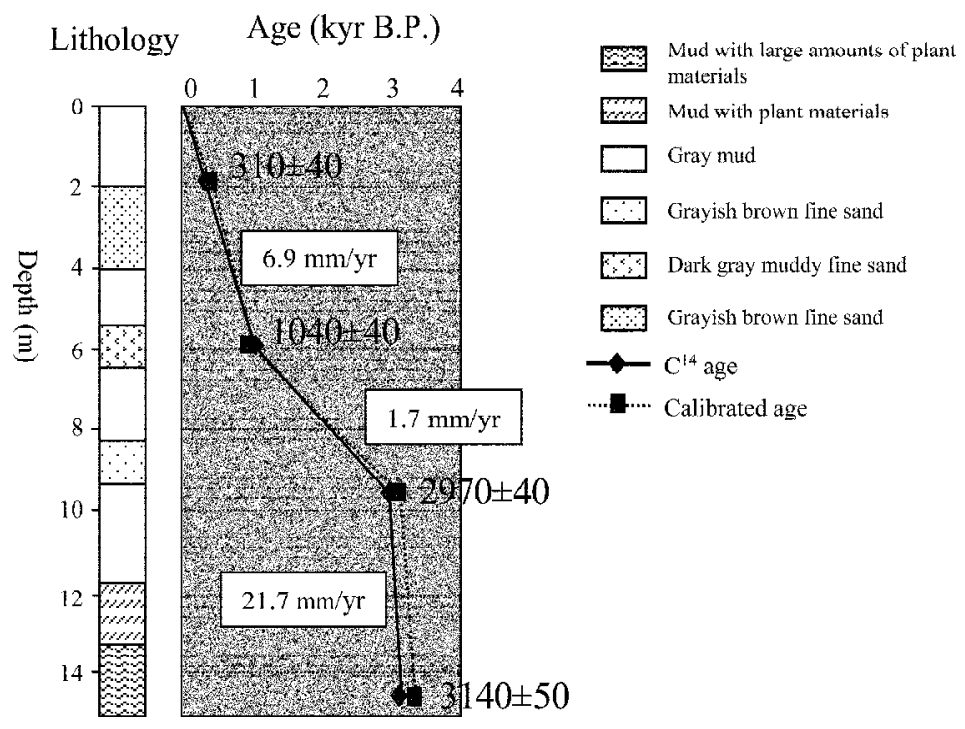

Fig. 2. Columnar section and the depth-age curve of the upper $15 \mathrm{~m}$ of the Wuyuan Core. Sedimentation rates are calculated by linear interpolation between ${ }^{14} \mathrm{C}$ dates.

Table 1. AMS ${ }^{14} \mathrm{C}$ age data from the Wuyuan Core.

\begin{tabular}{ccccc}
$\begin{array}{c}\text { Depth } \\
(\mathrm{m})\end{array}$ & $\begin{array}{c}{ }^{14} \mathrm{C} \text { age } \\
(\mathrm{yr} \text { B.P. })\end{array}$ & $\begin{array}{c}\text { 1-sigma cal. age } \\
\text { range (yr B.P.) }\end{array}$ & Material & Lab. Number \\
\hline $1.80-1.82$ & $310 \pm 40$ & $430-310$ & charcoal & Beta-176348 \\
$5.92-5.95$ & $1040 \pm 40$ & $1050-930$ & charcoal & Beta-176349 \\
$9.50-9.55$ & $2970 \pm 40$ & $3240-3080$ & plant material & Beta-176350 \\
$14.50-14.55$ & $3140 \pm 50$ & $3440-3270$ & plant material & Beta-176351 \\
\hline & &
\end{tabular}




\section{RESULTS AND DISCUSSIONS}

\subsection{Pollen Record}

The flora of the Ilan region is diverse. Over 95 taxa of fossil pollens and spores were identified in the pollen diagrams from the Wuyuan Core; these were composed of surrounding upland and local lowland plant communities. The regional upland vegetation inferred from the pollen record was a subtropical evergreen forest dominated by various species of Castanopsis, Quercus, and Alnus, along with Bischoffia, Myrica, Ardisia, Engelhardia, Lagerstroemia, Cephalanthus, and Barringtonia. It was similar to the prevailing forest that exists in the region today (Kuo 1993). The contribution of pollen from the local wetland plant communities should also constitute a major portion of pollen assemblage in the Wuyuan Core. For simplification, Fig. 3 shows percentages of major taxa on the basis of total pollen and spores. The percentages of arboreal taxa, based on total arboreal pollen only, are shown in Fig. 4.

The pollen record has been divided into five local assemblage zones, which suggests several significant changes in vegetation during the last 3500 years.

Zone WY5 (15.0 $13.6 \mathrm{~m}$; ca. 3500 to ca. $3350 \mathrm{yr}$ B.P.): Zone WY5 is marked by high percentages of Bruguiera in the lower section, which was then replaced by spores of Acrostichum in the upper section (Fig. 3). Both Bruguiera and Acrostichum are mangrove taxon and not found in Ilan today, but the latter was reported to have occurred in the estuary of the Tanshui River, northern Taiwan in the $19^{\text {th }}$ century (Kuo 2001). Pollen of arboreal taxa, distributed in the surrounding hills and mountains, such as Castanopsis, Quercus, Myrica, and Ardisia, appear to be relatively common and diverse in this zone of the core, whilst the percentages of lowland taxa such as Bischoffia, Lagerstroemia, and Cephalanthus are at their lowest values for the entire core (Figs. 3, 4).

Zone WY4 (13.6 $9.45 \mathrm{~m}$; ca. 3350 to ca. 3100 yr B.P.): Zone WY4 is characterized by the predominance of local wetland vegetation, especially Poaceae, Cyperaceae, and Typha (Fig. 3). The mangrove and brackish-tolerant taxa that dominated in the former zone, no longer exist. Upland arboreal taxa reach their highest values during this interval (Fig. 4). Pollen taxa common in the lowlands remain rare; however, a steady increase of Alnus occurs in the upper part of this zone. It is remarkable that there are two abrupt rises in percentages of monolete type fern spores at depths of 10.5 and $9.7 \mathrm{~m}$ respectively (Fig. 3), which probably indicate changes in humidity.

Zone WY3 (9.45 $7.55 \mathrm{~m}$; ca. 3100 to ca. 2000 yr B.P.): Zone WY3 is characterized by an obvious increase in Alnus (Figs. 3, 4). The percentage of Alnus, at low values in the previous zones, increases to its highest value in this zone. Moreover, arboreal taxa, which probably came from the surrounding highlands, are less than that of in WY4 (Figs. 3 and 4). Pollen taxa, common in lowlands, such as that of Bischoffia, Lagerstroemia, and Barringtonia, are present but rare. Pollen of local wetland vegetation (Poaceae and Cyperaceae) remains dominant even though Poaceae slightly decreases and aquatics are minor during this interval (Fig. 3). After dramatically increasing in WY4, the monolete fern spores decrease steadily in this zone.

Zone WY2 (7.55 $4.0 \mathrm{~m}$; ca. 2000 to ca. 700 yr B.P.): Zone WY2 is marked by a decrease in wetland vegetation, especially Cyperaceae (Fig. 3). The percentage of Alnus main- 


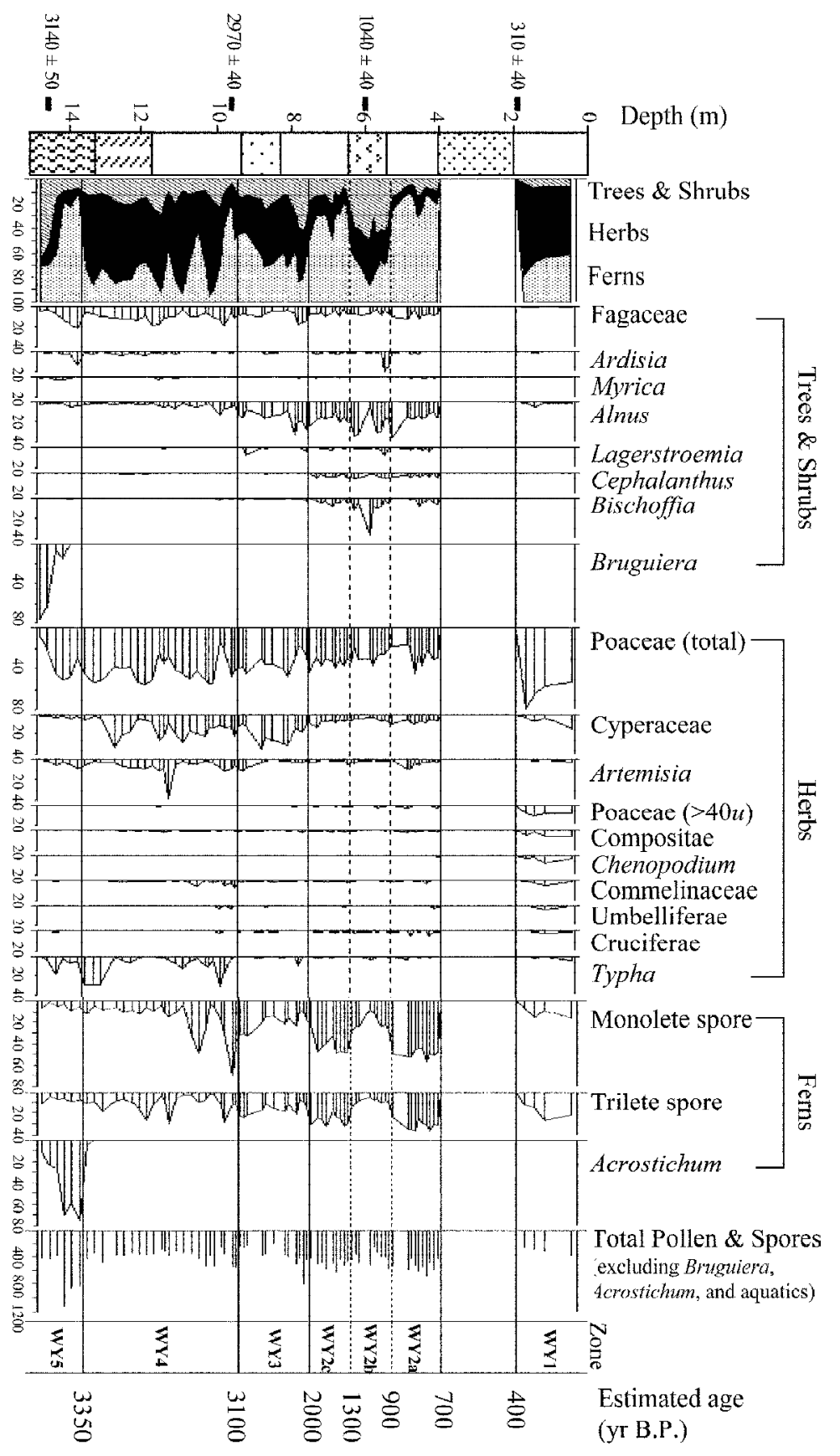

Fig. 3. Pollen diagram of selected taxa for the Wuyuan Core. Percentages of arboreal and herbs taxa are based on the pollen sum. Percentages of spores are based on gross pollen and spore sum. 


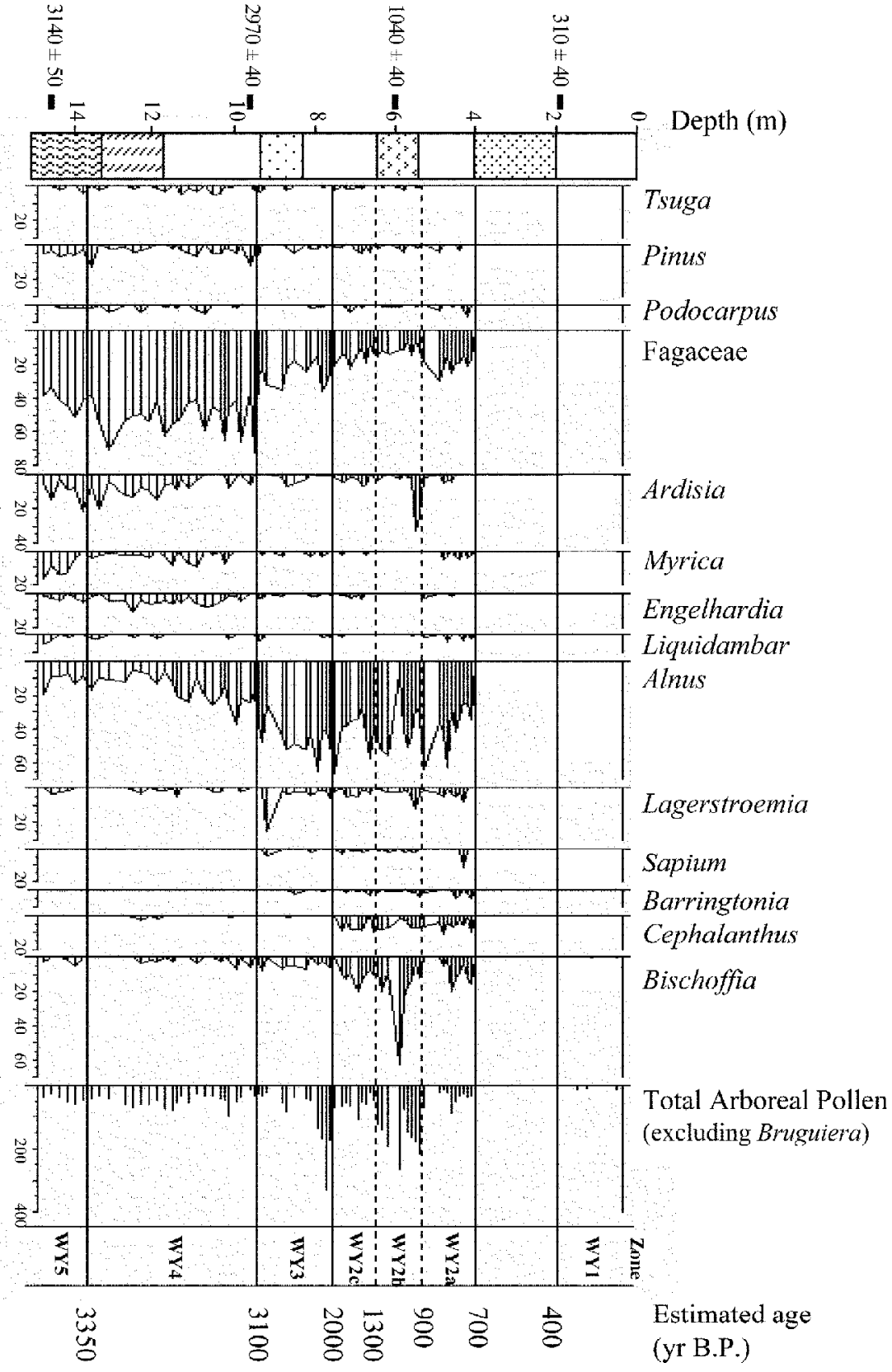

Fig. 4. Pollen diagram of selected arboreal taxa for the Wuyuan Core. The pollen sum includes all arboreal pollen excluding Bruguiera. The record from a depth above $2 \mathrm{~m}$ is not included due to the arboreal pollens being very few. 
tains its high value in this zone (Figs. 3, 4). In addition, pollen of lowland taxa such asBischoffia, Cephalanthus, and Barringtonia become more prominent and important. This zone is further divided into three subzones, WY2a, WY2b, and WY2c, based on the vicissitude of the fern spores (Fig. 3). The percentages of fern spores, mainly monolete type, increase substantially in Subzone WY2c (7.55 6.45 m; ca. 2000 to ca. 1300 yr B.P.). After a depression in Subzone WY2b (6.45 $5.35 \mathrm{~m}$; ca. 1300 to ca. $900 \mathrm{yr}$ B.P.), they rise again in Subzone WY2a (5.35 4.00 m; ca. 900 to ca. 700 yr B.P.). An astonishingly high value of Bischoffia and a decrease in fern spores indicate something unusual in Subzone WY2b (Figs. 3, 4). The high percentages of fern spores and Bischoffia will be discussed below.

Zone WY1 (2.0 0.5m; ca. 400 yr B.P. to recent): Zone WY1 is characterized by an increase in taxa associated with human disturbance. Poaceae pollen increases abruptly, together with other weeds (e.g., Compositae, Chenopodiaceae, Umbelliferae, and Cruciferae) likely indicating human impact during this interval (Fig. 3). Poaceae pollen, with diameters larger than 40 micron, is probably consistent with crop plants and reaches its highest value in percentage terms. Moreover, pollens of forest elements reach their lowest values in this zone (Fig. 3).

\subsection{Interpretation of Vegetation and Environment}

The pollen diagram from the Wuyuan Core of Ilan implies paleovegetational changes during the late Holocene. At approximately 3500 to 3350 yr B.P. (Zone WY5), high percentages of Bruguiera and Acrostichum suggest that mangrove and brackish-tolerant taxa dominated at the coring site of Wuyuan. At present, mangrove forests, mainly consisting of Kandelia candel, Rhizophora mucronata, Avicennia marina, and Lumnitzera racemosa excluding Bruguiera sp., are generally well distributed along the coasts of western Taiwan but never found in the Ilan region (Kuo 1995). Bruguirea gymnorrhiza was reported to occur in southern Taiwan forty years ago, but is extinct now (Hsieh 1984). Acrostichum aureum, which is distributed locally in southeastern Taiwan today, occurred at the coastal area of Tanshui, northern Taiwan about 120 years ago (Kuo 2001). Both Bruguiera and Acrostichum have been found in core samples from the Taipei Basin and Ilan region in the first author's works although they are absent in present vegetation. A plausible explanation is that they were previously more widespread, and could have been a dominated component at Wuyuan area prior to $3350 \mathrm{yr}$ B.P. It probably suggests that before ca. $3400 \mathrm{yr}$ B.P., the coring site was situated either in a brackish to freshwater environment with some marine influence, or was more close to the sea than at present. It implies a local marine transgression and the subsequent regression of the Ilan region prior to 3500 years ago.

The period between ca. 3350 and ca. 3100 yr B.P. (Zone WY4), characterized by the remarkable increase of Poaceae, Cyperaceae and freshwater aquatic plants, suggests the widespread development of wetland marshes in the vicinity of Wuyuan. In addition, the disappearance of Bruguiera and Acrostichum probably implies an eastward shifting of the coastline. The regional upland vegetation inferred from pollen zone WY4 is a broadleaved evergreen forest dominated by various species of Fagaceae. Alnus possibly represents a minor forest component on the still open lowlands and hills bordering the Ilan Plain. The forest develop- 
ment could be limited by hydrological and pedological factors rather than climate.

The period from ca. 3100 to ca. $2000 \mathrm{yr}$ B.P. (Zone WY3) is marked by the common occurrence of Alnus, which is considered to be a pioneer taxon, probably suggesting a progressive expansion of forest in to the lowlands. Although the pollen of local wetland vegetation remains significant, the decrease of Poaceae and aquatics indicates the shrinking of the wetland marsh. It suggests the gradual replacement of taxa chiefly Fagaceae by that of Alnus and lowland vegetation. These vegetation changes could have been a response to the progressive development of the fluvial plain.

By ca. 2000 yr B.P., the dominance of Alnus and the appearance of lowland vegetation such as Cephalanthus probably indicates the shift from a marsh to a terrestrial environment at the coring site. Similarly, the low value of local wetland member, Cyperaceae, in Zone WY2 also likely indicates a reduction in marshy areas. The occurrence of Bischoffia pollen in Subzone WY2b, which is a common component of modern lowland taxon and is closely related to human inhabitation, very likely reflects human activity between ca. 1300 and ca. $900 \mathrm{yr}$ B.P. although to discriminate climatic influence from human influence is sometimes difficult. It is fairly consistent with archaeological evidence record that three sites nearby Wuyuan appear to have been settled by people around this period (Liu 1995, 2000).

The pollen-scant sediments between 2.0 and $4.0 \mathrm{~m}$ in depth are oxidized and too coarse to preserve pollen and spores. Nevertheless, the stratigraphical data from Wanshan archaeological site, which is situated on the hill about $4 \mathrm{~km}$ southwest of Wuyuan, exhibits the phenomena of redeposition of artifacts and is likely to have been associated with a period of heavy rainfall from about 750 to $300 \mathrm{yr}$ B.P. (Liu et al. 2002).

About 400 years ago (Zone WY1), significant forest clearing and site occupation occurred as indicated by the pollen data from the Wuyuan Core. The increase of large-sized Poaceae (diameter $>40$ micron) probably reveals that agriculture was already established in the Ilan region, as evidenced from archaeological research, even though the evidence of domesticated plant cultivation is not distinct from the pollen record.

\subsection{Climatic Interpretation}

Variations in both temperature and precipitation are often considered as the basic criteria for climatic change. However, the precipitation and effective moisture, which are even more important in controlling biological productivity, are sensitive to changes in the East Asian monsoon (Wu et al. 1994; An et al. 2000). The pollen record from the Wuyuan core indicates temperature change, inferred from the abundance of arboreal vegetation, remained ambiguous during the last 3500 years. However, fluctuations in humidity were relatively obvious. Previous pollen studies revealed a close relationship between fern spores and the humid climate in Taiwan (Kuo 1994; Liew and Huang 1994; Liew et al. 1997; Liew et al. 1998; Liew and Hsieh 2000). The high percentages of fern spores in the pollen diagram, especially when they were dominant, are typical indications of high humidity. Accordingly, the fern spores (excluding Acrostichum) in the Wuyuan Core are considered to be a bioclimatic index for interpreting humidity trends. Wet periods are recognized by high values for ferns spores, in contrast to drier periods where values are lower. Thus, the record shows that wetter periods prevailed 
around ca. 3200 to ca. $3100 \mathrm{yr}$ B.P., ca. 2000 to ca. 1300 yr B.P. and after ca. 900 yr B.P., respectively (Fig. 5).

The climate of the Ilan region is strongly influenced by monsoons due to its geographic and topographic characteristics. In most parts of this island beyond Ilan, higher precipitation intervals during the Holocene were mainly induced by typhoons due to a strengthened summer monsoon. However, precipitation in Ilan needs further consideration as the region faces the winter monsoon directly and high levels of precipitation currently occur between September and November. It is quite conceivable that the relative abundance of fern spores could be explained by a wetter climate and this interpretation implies a stronger monsoon (i.e., possibly a winter monsoon) system during these intervals. The monsoon could have been unstable during the past 3200 years. It probably strengthened twice during a short period around ca. 3200 to ca. 3100 yr B.P. Following a gradual decrease between ca. 3100 and ca. 2000 yr B. P., the monsoon strengthened again at around $2000 \mathrm{yr}$ B.P. Thereafter, it steadily strengthened until ca. 1300 yr B.P., then decreased again until ca. 900 yr B.P. Since then, the monsoon has strengthened.

Inferred climate trends are also based on local hydrological conditions deduced from arboreal pollen concentrations and magnetic susceptibility (Fig. 5). Pollen concentration gives the palaeoecological information about sedimentological changes. The arboreal pollen con-
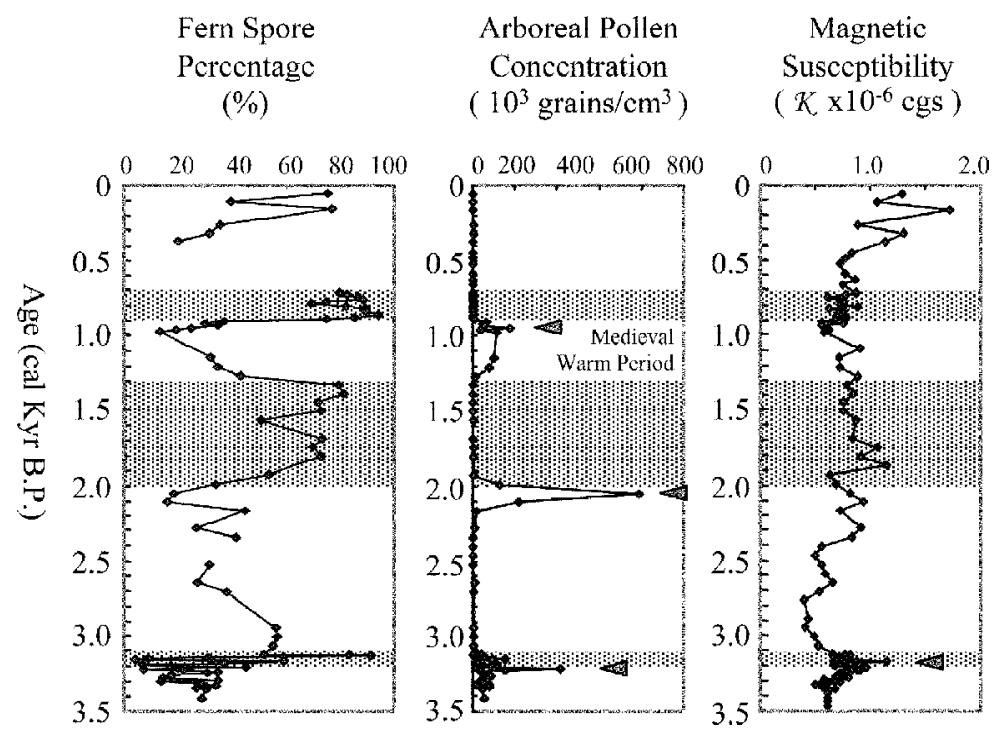

Fig. 5. Spore percentages, arboreal pollen concentrations, and magnetic susceptibility curves for the Wuyuan Core. Shadow areas show the wetter periods inferred from the fern spores record. The high values of arboreal pollen concentrations around ca. 1300 to ca. $900 \mathrm{yr}$ B.P. probably imply to the Medieval Warm Period. 
centration curve from the Wuyuan Core shows that some extra-high signals took place at ca. 3200 yr B.P., ca. 2050 yr B.P., and ca. 950 yr B.P. respectively, which probably implies relatively unusual amounts of pollen influx from upland regions. These signals occur immediately prior to the wetter intervals deduced from the peaks in fern spores and probably record the trigger time of the strengthened monsoon. Furthermore, high values of arboreal pollen concentration around ca. 1300 to ca. 900 yr B.P. (ca. 700 to ca. 1100 AD) indicating higher vegetation productivity could be coincident with part of the Medieval Warm Period.

Magnetic susceptibility is controlled mainly by superparamagnetic grains, which are usually present as a detrital component. This occurs as rainfall enhances the transport of detrital sediments from the soil surface, resulting in an increase in superparamagnetic grain content in sediments. Thus, similar to the pollen concentration record, it serves as complementary evidence of climatic variations in which a remarkable magnetic enhancement often occurs at the beginning of a wetter period. The magnetic susceptibility data from the Wuyuan Core shows a magnetic enhancement at a depth of $10.5 \mathrm{~m}$, which corresponds to the climate trend interpreted from the pollen record around $3200 \mathrm{yr}$ B.P. (Fig. 5). However, such signals were obscure at ca. 2000 and ca. 900 yr B.P., and differed from the trend in arboreal pollen concentrations. This could be due to the development of the fluvial plain which may have resulted in a smoothing of the magnetic enhancement in sediments.

Wetter periods over these several millennia in Ilan may indicate the strengthening of both the summer and winter monsoons, or might rather indicate an enhanced winter monsoon especially since these periods are corresponding to times of cooler and/or drier intervals of Mainland China (Figs. 6, 7) (Chu 1972; Wang 1980; Zhang 1984; Wang and Zhang 1992; Fang 1993). Liew et al. 2002 presented pollen evidences from alpine lakes in central Taiwan showing cold/dry and warm/wet fluctuations in the response of vegetation during the past ca. 4000 cal yr B.P. Significant cooler/drier trends were proposed for three prominent intervals: 3700 to 2400 yr B.P., 1600 to $1100 \mathrm{yr}$ B.P., and 700 to $150 \mathrm{yr}$ B.P., with warmer/wetter periods between these intervals (Liew and Huang 1994; Liew et al. 2002). Wide and well developed river terraces existing in the Lanyang drainage basin, northeastern Taiwan, also show a widespread aggradational episode range from ca. 2120 to 1540 yr B.P. (Fig. 8), which possibly suggests an increasing frequency of typhoons or precipitation during this period (Hsieh et al. 1997; Liew and Hsieh 2000). The geochemistry data from alpine lake sediments (the ChiaMin Lake, $3310 \mathrm{~m}$ altitude) in central Taiwan indicates that the warm period corresponded to the Medieval Warm Period occurring around 750 to 1320 AD (Fig. 9) (Lou 1996). These results are approximately consistent with the climatic trends inferred from the Wuyuan Core although more intensive dating is necessary.

\section{CONCLUSIONS}

The pollen record from the Wuyuan Core provides a late Holocene vegetation history of local wetland and regional uplands of the Ilan region, northeastern Taiwan. At about $3500 \mathrm{yr}$ B.P., the Wuyuan area fluctuated between a brackish and freshwater environment with marine influence, a period that existed probably just after a marine excursion. By ca. 3350 to ca. 2000 


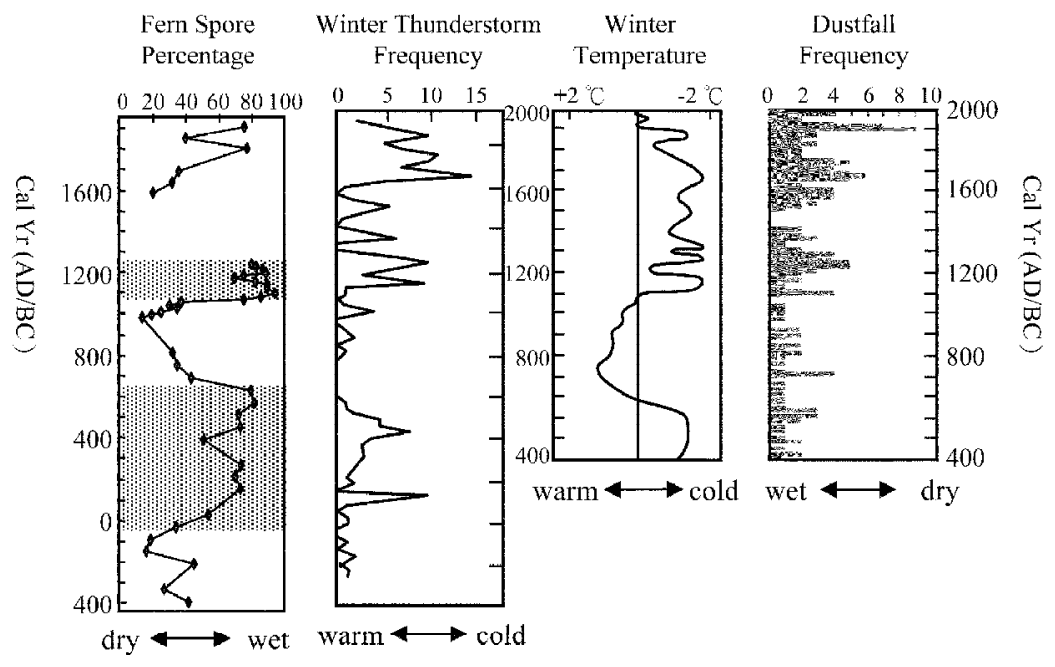

Fig. 6. Spore percentages (this study), winter thunderstorm frequency (Wang 1980), winter temperature (Chu 1972), and dustfall frequency (Zhang 1984) curves. The wetter periods in Ilan correspond to the time of cooler and drier intervals in Mainland China.

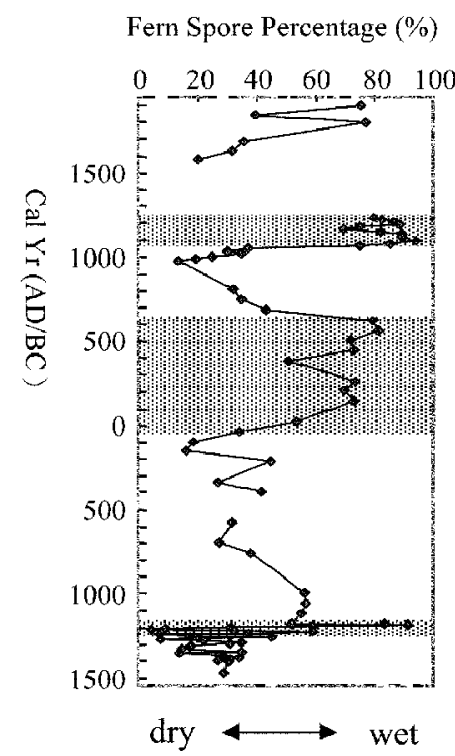

Frequency $(\%)$

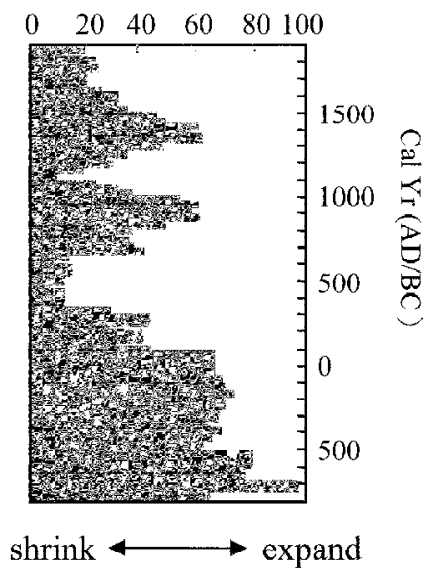

Fig. 7. Spore percentages's curve (this study) and lake level variations in Mainland China (Fang 1993). The wetter periods in Ilan correspond to periods of lake shrinking. 


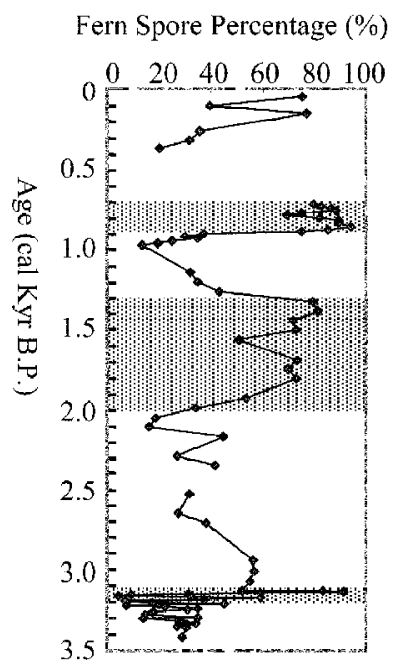

Chronology of Lanyang Terraces

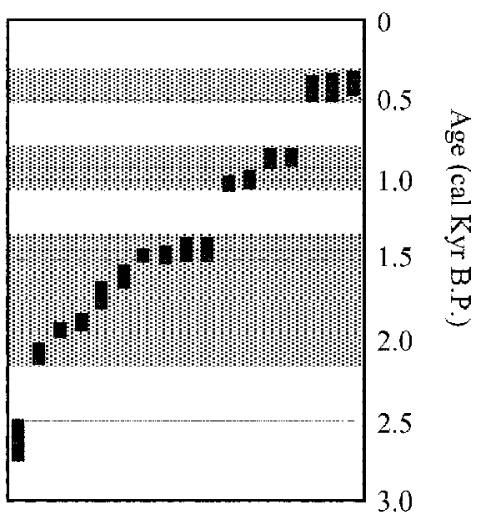

Fig. 8. Spore percentages' curve (this study) and the chronology of the Lanyang Terraces (Chen 1996; Hsieh et al. 1997; Chyi et al. 1998). The wetter periods in Ilan are approximately consistent with the aggradational episodes in the Lanyang drainage basin, which probably imply an increasinging frequency of typhoons or precipitation during these periods (Hsieh et al. 1997; Liew and Hsieh 2000).

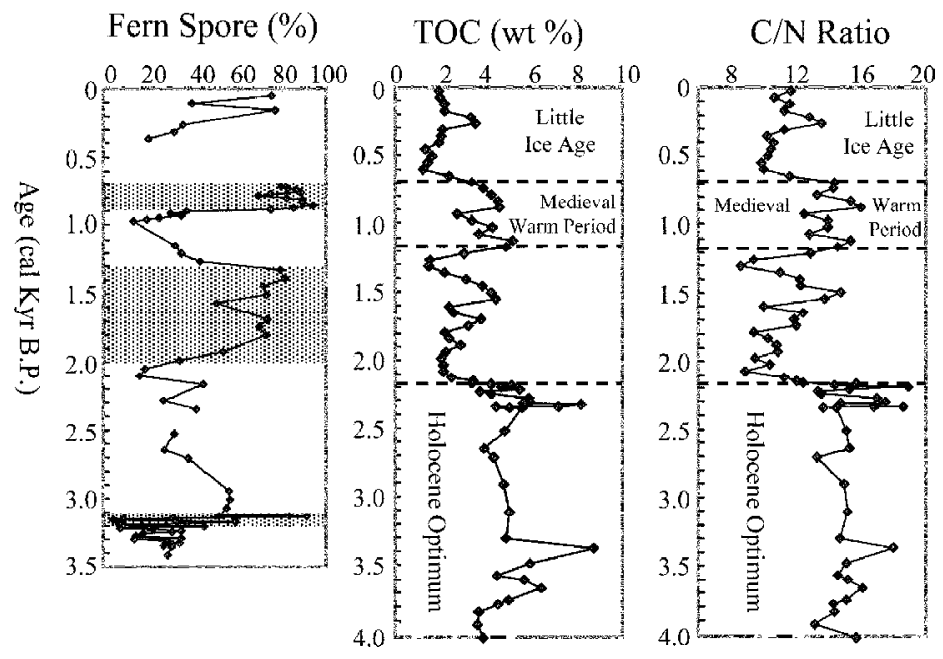

Fig. 9. Spore percentages' curve (this study) and the geochemistry data from Chia-Min Lake (Lou 1996). The climatic trends inferred from the fern spores record are approximately consistent with the results from the alpine lake. 
yr B.P. the fan delta prograded eastward, the landscape in the lowlands was probably a mosaic of forests, swamps, and marshes; while in the uplands it was a subtropical evergreen forest similar to the one existing there today. And since then, the present fluvial plain has developed. Around ca. 1300 to ca. 900 yr B.P. human-induced vegetation registered in the pollen record. Human influence and the expansion of agriculture in the Ilan Plain are indicated by a significant reduction in arboreal pollen and an increase in herbaceous pollen since ca. $400 \mathrm{yr}$ B.P.

In spite of the ambiguity in temperature changes within the several millennia inferred from the pollen record, the fern spore record provides insight into humidity conditions and probably implies monsoon trends. Over the past 3500 years, significant intensification in monsoons was observed for three prominent intervals: 3200 to $3100 \mathrm{yr}$ B.P., 2000 to $1300 \mathrm{yr}$ B.P., and from $900 \mathrm{yr}$ B.P. to the present. The Medieval Warm Period was also proposed based on the arboreal pollen concentration record at around ca. 1300 to ca. $900 \mathrm{yr}$ B.P. The climatic conditions brought about by monsoon trends are likely to have constituted critical factors in the environment and type of livelihood experienced by people living in the Ilan region.

Acknowledgments The authors would like to express our sincere thanks to the Central Geological Survey for providing samples and $\mathrm{C}^{14}$ dates of the sediment core. We would also like to thank Profs T. C. Huang, S. C. Huang, and T. K. Liu for their many useful comments and suggestions.

\section{REFERENCES}

An, Z., S. C. Porter, J. E. Kutzbach, X. Wu, S. Wang, X. Liu, X. Li, and W. Zhou, 2000: Asynchronous Holocene optimum of the East Asia monsoon. Quat. Sci. Rev., 19, 743762.

Central Geological Survey, 2001: Report of "Groundwater Monitoring Network in Taiwan"the hydro-geology survey in the Chianan Plain and Lanyang Plain. Central Geol. Survey Press, Taipei, 212pp. (in Chinese)

Central Weather Bureau, 2002: Summary report of meteorological data Taiwan, V.6. Central Weather Bureau Press, 55pp. (in Chinese)

Chen, B. L., 1996: Geomorphic evolution of alluvial fans in the upper Lanyang valley. Master thesis, Dept. of Geography, Nat. Taiwan Univ., 155pp. (in Chinese)

Chen, T. Y., 2000: Plant ecology of low land area in northern Taiwan. In: H. F., Yen (ed.) Botanical garden resources and its management, Nat. Museum of Natural Sci. Press, 9-33. (in Chinese)

Chen, W. S., 2000: The study of sediments, depositional environments and stratigraphic correlations in the Lanyang Plain. Report of "Groundwater Monitoring Network in Taiwan project", Central Geol. Survey Press, Taipei, 48pp. (in Chinese)

Chiang, S. H., 1995: Climatic change in Ilan. In: Proc. Ilan Res. Symp. (1), Ilan, 10-35. (in Chinese)

Chu, K. C., 1972: A preliminary study on the climate fluctuations during the last 5000 years in China. Acta Archaeologica Sinica, 1, 15-38. (in Chinese) 
Chyi, S. J., Q. C. Sung, B. L. Chen, M. L. Hsieh, H. Tsai, and J. K. Fu, 1998: The evolution of alluvial fans along the upper reach of Lanyang River. Environ. Worlds, 2, 137-150. (in Chinese)

Fang, J. Q., 1993: Lake evolution during the last 3000 years in China and its implications for environment change. Quat. Res., 39, 175-185.

Hsieh, C. L., 1984: Surveys of mangrove in Kaohsiung Bay. Kaohsiung-wen-xian. 18/19, 251-268. (in Chinese)

Hsieh, M. L., S. J. Chyi, B. L. Chen, and P. M. Liew, 1997: Holocene river terraces in the Lanyang and Erhjen Rivers and their climatic implications. In: Program and expanded abs. of Conf. Geomorphol. and Environ. Edu. across the Taiwan Strait, Taipei, 65-70.

Huang, S. C., 1998: Report of survey and excavation for cultural sites form Tou-cheng to Suao, Taipei to Ilan Freeway. MTC Taiwan Area Nat. Expressway Engineering Bureau Press, 31pp. (in Chinese)

Kuo, C. M., 1993: Plant ecology of Dongshan He and Lanyang Chi. Yilan County Government Press, 41pp. (in Chinese)

Kuo, C. M., 2001: An introduction to ferns. Yuan-Liou Publications, Taipei, 183pp. (in Chinese)

Kuo, C. M., 1994: Pollen analysis of lake sediments in the Toshe Basin since older than 10 Ka. Master thesis, Dept. of Geol., Nat. Taiwan Univ., 82pp. (in Chinese)

Kuo, Z. Y., 1995: A field guidebook of mangrove in Taiwan. Da-Shu Publications, Taipei, 195pp. (in Chinese)

Lai, Z. H., and M. L. Hsieh, 2003: Late-Quaternary vertical rock-movement rates of the coastal plains of Taiwan. In: Abs., 2003 Ann. Meeting Geol. Soc. China, 119.

Letouzey, J., and M. Kimura, 1986: The Okinawa Trough genesis, structure and evolution of the backarc basin developed in a continent. Mar. Petrol. Geol., 2, 111-130.

Liew, P. M., and M. L. Hsieh, 2000: Late Holocene (2 ka) sea level, river discharge and climate interrelationship in the Taiwan region. J. Asian Earth Sci., 18, 499-505.

Liew, P. M., and S. Y. Huang, 1994: A 5000-year pollen record from Chitsai Lake, central Taiwan. TAO, 5, 411-419.

Liew, P. M., C. Y. Huang, and M. H. Tseng, 1997: Preliminary study on the late Quaternary climatic environment of the Taipei Basin and its possible relation to basin sediments. J. Geol. Soc. China, 40, 17-30.

Liew, P. M., S. Y. Huang, and C. M. Kuo, 2002: Climatic changes of recent several millennia in Taiwan based on pollen record. In: Symposium for the retirement of Profs. Tsien, Hsien Ho. and Lo, Huann Jih. of the Dept. of Geosciences, Nat. Taiwan Univ., 165170. (in Chinese)

Liew, P. M., C. M. Kuo, S. Y. Huang, and M. H. Tseng, 1998: Vegetation change and terrestrial carbon storage of eastern Asia during the last glacial maximum as indicated by new pollen records of northern Taiwan. Global Planet. Change, 16, 85-94.

Liu, C. C., 1995: The Ilan Plain and the southwestward extending Okinawa Trough.J. Geol. Soc. China, 38, 229-242.

Liu, Y. C., 1995: Prehistoric culture type of Ilan region. In: Proc. Ilan Research Symp. (1), Ilan, 38-56. (in Chinese) 
Liu, Y. C., 2000: The importance of Ilan archaeology in Taiwan. I-Lan J. History, 43, 3-27. (in Chinese)

Liu, Y. C., S. J. Chiu, R. C. Dai, C. Y. Li, and C. S. Liao, 2002: Report of salvage excavation on the Wanshan Site, Yilan County. Yilan County Government Press, 144pp. (in Chinese)

Lou, J. Y., 1996: The distribution of elements in the sediments of alpine lakes in Taiwan and the paleoclimate. Ph. D. thesis, Nat. Sun Yat-Sen Univ., 194pp. (in Chinese)

Moore, P. D., J. A. Webb, and M. E. Collinson, 1991: Pollen analysis. $2^{\text {nd }}$ ed., Blackwell Scientific Publications, London, 216pp.

Stuiver M., P.J. Reimer, E. Bard, J.W. Beck, G.S. Burr, K.A. Hughen, B. Kromer, G. McCormac, J. van der Plicht, and M. Spurk, 1998: INTCAL98 Radiocarbon Age Calibration, 24000-0 cal BP. Radiocarbon, 40, 1041-1083.

$\mathrm{Su}, \mathrm{H}$. J., 1984: Studies on the climate and vegetation types of the natural forests in Taiwan (II)-altitudinal vegetation zones in relation to temperature gradient. Quat. J. Chinese Forestry, 17, 57-73.

Suppe, J., 1984: Kinematics of arc-continent collision, flipping of subduction, and back-arc spreading near Taiwan. Mem. Geol. Soc. China, 6, 21-33.

Wang, P. K., 1980: On the relationship between winter thunder and the climatic change in China in the past 2200 years. Climatic Change, 3, 27-46.

Wang, P. K. and D. Zhang, 1992: Recent studies of the reconstruction of East Asian monsoon climate in the past using historical literature of China.J. Meteor. Soc. Japan, 70, 423446.

Wu, X., Z. An, S. Wang, X. Liu, X. Li, W. Zhou, J. Liu, J. Lu, S. C. Porter, and J. E. Kutzbach, 1994: The temporal and spatial variation of East Asia summer monsoon in Holocene Optimum in China. Quat. Sci., 1994, 24-37. (in Chinese)

Yeh, Y. H., C. H. Lin, and S. W. Roecker, 1989: A study of upper crustal structures beneath northeastern Taiwan: possible evidence of the western extension of Okinawa Trough. Proc. Geol. Soc. China, 32, 139-156.

Zhang, De'er, 1984: Synoptic-climatic studies of dustfall in China since historical times. Scientia Sinica, B27, 825-836. 